\title{
ROLE OF MDCT IN ASSESSMENT OF EARLY POST-OPERATIVE COMPLICATIONS IN SLEEVE GASTRECTOMY IN BARIATRIC PATIENTS
}

\author{
Mohamed Shaker Ghazy, Amr Mahmoud Ahmed., Mohamed Mahfouz Mohamed, \\ and Abou Bakr Tawfik Ahmed Abdou
}

\begin{abstract}
Department of Radiology and, Department of General Surgery Faculty of Medicine, Ain Shams University, Cairo, Egypt

\section{Corresponds:}

Abou Bakr Tawfik Ahmed

Background: laparoscopic sleeve gastrectomy (LSG) is one among different bariatric surgeries, which became an effective treatment method for morbid obesity. CT may be performed after laparoscopic sleeve gastrectomy to assess acute complications as staple line leakage, abscesses, hematomas, portal vein thrombosis $(P V T)$, splenic injury or infarction.
\end{abstract} Abdou

e.male:

abubakr141185@gmail.com.

Tel.: 01005473085

Receved: 14/2/2019

Accepted: 7/3/2019

Aim of the study: was to assess the value of multi-detector CT in the evaluation of the suspected early complications of LSG.

Patients and Methods: This study was an observational study, included 25 patients who underwent LSG and CT was done for them to detect any suspected complication even in the presence of negative upper gastrointestinal (UGI) series.

Results: MDCT detected complication in 15 patients out of the 25 patients (60\%), with no mortality. Leakage occurred in 16\%, abscess in $8 \%$, hematoma in $8 \%$, splenic injury, splenic infarction and PVT in $4 \%$ each.

Conclusions: $C T$ is an important imaging tool to diagnose suspected complications of laparoscopic sleeve gastrectomy procedure and should be used to ensure accurate diagnosis or in the case of mismatch between symptoms and routine upper GIT studies.

Key Words: multi detector CT; laparoscopy; sleeve gastrectomy; minimally-invasive; Bariatric.

\section{INTRODUCTION}

Morbid obesity is expanding worldwide, and increasing levels of obesity are associated with increasing risk of comorbidities and death ${ }^{[1]}$.

Obesity is a universal disease of growing prevalence that has been acquiring alarmingly epidemic proportions, affecting more than one billion adults and being one of the main public health problems of modern society. Obesity is a disease classified according to WHO (World Health Organization) through the body mass index
(BMI). BMI over $40 \mathrm{~kg} / \mathrm{m} 2$ is pronounced as morbid obesity ${ }^{[2]}$.

Excess weight is associated with the raise of morbidity and mortality, and this risk rises progressively according to the weight gain. Obese individuals die more from diseases related to the cardiovascular system, especially stroke and acute myocardial infarction, when compared to individuals with normal weight ${ }^{[2]}$.

The negative impact of obesity is related not only to morbidity and mortality, but also to quality of life, (the person's physical 
health, and psychological state and social relationships) ${ }^{[3]}$.

Surgical treatment for obesity began in the middle of the $20^{\text {th }}$ century. Operations for obesity are classified into three types: restrictive, malabsorptive, and mixed. The purpose of these operations was to achieve early satiety by reducing stomach capacity and appetite. Recently, Laparoscopic sleeve gastrectomy (LSG) has gained popularity as a primary operation for the treatment of morbid obesity ${ }^{[4]}$.

The laparoscopic sleeve gastrectomy (LSG) is a restrictive bariatric procedure which involves subtotal gastric restriction of the body and the fundus to create along tubular gastric conduit. The purpose of this operation was to achieve early satiety by reducing stomach capacity and appetite ${ }^{[5]}$.

Radiological assessment is important in the first post-operative period to exclude early complications and is currently based on upper gastrointestinal gastrografins wallow studies and computed tomography $\operatorname{scan}^{[6]}$.

Complications are classified as early postoperative complications ( $<30$ days) and late post-operative complications $\quad>30$ days). Examples of early post-operative complications are staple line leakage, gastric pouch stenosis, abscess formation, wound infection, gastric fistula, and delayed gastric emptying. Examples of late post-operative complications includes dilatation of the gastric pouch and weight gain ${ }^{[7]}$.

The most important post-operative complications are leaks. It classified into early, occurring on the first-third postoperative day (POD), intermediate, noted on the fourth-seventh POD, and late, occurring later than the eighth POD. Leaks are also classified according to their etiology into staple line failure leaks and ischemic leaks ${ }^{[8]}$.

CT examinations are ideally performed with both oral and intravenous contrast agent. Because of the size and girth of bariatric patients, it may be necessary to adjust technical factors such as Kilo-voltage, mill- amperage, field of view, and collimation thickness. CT of the abdomen is considered as a part of diagnostic work up of patients with suspected leak and presence of abdominal collection or free fluid, extravasations of contrast into the abdominal cavity or the drain tube or presence of pneumo-peritonumare diagnostic findings of leakage or fistula ${ }^{[9]}$.

\section{AIM OF THE WORK:}

The aim of this study was to assess the role of MDCT in assessment of early postoperative complications of sleeve gastrictomy which has an essential diagnostic role in determining appropriate patient management.

\section{PATIENTS AND METHODS}

This study is a prospective cohort study to evaluate the value MDCT in evaluation of early post-operative complications of laparoscopic sleeve gastrectomy.

\section{Patients:}

Twenty five patients post-sleeve gastrectomy referred by their surgeons with clinically or radiologically suspected complications were included in this study. Symptoms of clinically suspected complications included sudden tachycardia, hypotension, abdominal distension and severe persistent abdominal pain.

The examinations were done at the Radiology Department of Ain Shams University Hospital from December 2016 to December 2018.

Patients were selected on the basis of the following criteria: Post-sleeve gastrectomy obese patient of both sexes who were vitally stable and had clinically or radiologically suspected complications. 
Patient age between 18-50 years at the time of the survey.

Patients were excluded from this study on the basis of the following criteria: patients who had contra indications to contrast media, Patients who were vitally unstable, patients younger than 18 years or older than 50 years, patients who refused to participate in this study.

\section{Methods}

The imaging protocol that was done for the patients was as follows:

\section{Patient preparation:}

Patient fasted for six hours before the time of examinations. Patient arrived 15-30 minutes before CT scan. An informed consent form was given directly by the main researcher to the patient or his $1^{\text {st }}$ degree relative who read the form or it was read to $\mathrm{him} / \mathrm{her}$ by the main researcher who explained the whole details of the procedure. Assessment of patient's body weight and checking serum creatinine level were done. The patient was given a gown to wear and metallic items that produce artifact were removed. The patient was given detailed explanation of the procedure including the instructions to keep calm and how to hold his breath when needed. Intravenous wide bore cannula was installed. Patient swallowed $20 \mathrm{ml}$ of water-soluble contrast media diluted in $400 \mathrm{ml}$ water as tolerated, just before examinations. The patient was introduced to the MDCT machine, lying in supine position with head fixed and arm elevated up.

\section{CT Technique:}

Imaging was performed using a Toshiba CT 80 slice machine (Toshiba health care, Japan) or GE CT 64-slice scanning machine (GE health care USA). A tube voltage and a tube current were adjusted according to the size and girth of the patients. Unenhanced CT was performed to detect hemorrhage. A bolus of $100 \mathrm{ml}$ contrast media [omnipaque and $300 \mathrm{mg}$ Iodine/ml (Iohexol, GE health care Ireland, Cork, Ireland)] was injected followed by $30 \mathrm{ml}$ of normal saline injected at a rate of $3.5 \mathrm{ml} / \mathrm{sec}$ and delayed time 1-3 sec and then CT including arterial and venous phases was performed to detect other complications. The patient was asked to hold his breath. CT study of abdomen and pelvis started from the level of diaphragm and extended caudally to the level of symphysis pubis with reconstruction section and interval thickness of $5 \mathrm{~mm}$. The whole study took approximately 5-10 minutes. All image data were sent electronically to picture archiving and communication system workstation and images were reconstructed to coronal and sagittal images.

After examinations images were checked before patient leave. Patient was instructed to drink plenty of water to get rid of any remaining contrast media. All patients were monitored for any adverse effects. IV access was maintained for 30 minutes after examination. Emergency drugs were available and used in place in case of emergency (such as corticosteroids, antihistaminic).

\section{Outcome measures}

Data were gathered in an electronic database and analyzed. Parameters of interest were patient characteristics and postoperative complications.

Early surgical complications were defined as complications occurring during the first 30 days after LSG. The primary endpoint was the efficacy of CT scan examination in diagnosing surgical complications, as determined by sensitivity, specificity, and negative and positive predictive values. Secondary endpoints were the global rate of postoperative early surgical complications, including gastric staple line leak, bleeding or hematoma, abscess, splenic injury, Porto-mesenteric vein thrombosis and fistula. 
Approval to conduct this study was obtained from the Ethical and research committee of the Ain Shams university. Written informed consent was obtained from each patient.

\section{Statistical analysis:}

Data obtained from the present study were computed using Data were statistically described in terms of range, mean, frequencies and relative frequencies (percentages) when appropriate. All statistical calculations were done using computer programs Microsoft Excel (Microsoft Corporation, NY, and USA) and SPSS (Statistical Package for the Social Science; SPSS Inc., Chicago, IL, USA) statistical program.

\section{RESULTS:}

This study was conducted on 25 patient's post-sleeve gastrectomy referred by their surgeons. The examinations were done when complications were clinically or radiologically suspected. The majority of cases in this study were females (68\%) while males were $32 \%$. The age of patients ranged from 26 years to 46 years with mean age of 36 years (Table-1).

Table (1): Distribution of patients according to sex and age

\begin{tabular}{|c|c|c|}
\hline Sex & $\begin{array}{l}\text { Female } \\
\text { Male }\end{array}$ & $\begin{array}{l}17 \quad(68 \%) \\
8 \quad(32 \%) \\
\text { Total no. }=25\end{array}$ \\
\hline Age (years) & $\begin{array}{l}\text { Mean } \\
\text { Range }\end{array}$ & $\begin{array}{l}36 \pm 12.3 \\
26-46\end{array}$ \\
\hline
\end{tabular}

Results included 15 complications (in 25 patients) considering that some patients may be free of radiological findings of complications. The most common complication was gastric leak (16\%) (Fig. 1), followed by abscess formation (8\%), hematoma (8\%) (Fig. 2), Pleural effusion (8 $\%$ (Fig. 2), and Porto-mesenteric vein thrombosis was also seen in 2 patients $(8 \%)$ (fig. 3). MDCT examination was able to detect all 15 complications and showed sensitivity and specificity of $100 \%$ for each. (Table-2).

Table (2): Post-operative complications associated with LSG

\begin{tabular}{|l|c|c|}
\hline Complication & Number & $\mathbf{( \% )}$ \\
\hline Leak & 4 & $16 \%$ \\
\hline Abscess & 2 & $8 \%$ \\
\hline hematoma & 2 & $8 \%$ \\
\hline Pleural effusion & 2 & $8 \%$ \\
\hline $\begin{array}{l}\text { Porto-mesenteric vein } \\
\text { thrombosis }\end{array}$ & 1 & $4 \%$ \\
\hline Splenic infarction & 1 & $4 \%$ \\
\hline Splenic injury & 1 & $4 \%$ \\
\hline Wound infection & 25 & $60 \%$ \\
\hline $\begin{array}{l}\text { number of patient with } \\
\text { complications } \\
\text { Total patient number }\end{array}$ & $100 \%$ \\
\hline
\end{tabular}

In this study, Proximal third of the stomach was the commonest site for leaks and was found in 4 cases (fig. 1), and no cases of leaks were found at distal third of the stomach. (Table 3).

Table (3): time and site of leakage

\begin{tabular}{|l|l|l|l|}
\hline & & Number & $\%$ of total leaks \\
\hline Site & upper staple line & 4 & $100 \%$ \\
& lower staple line & 0 & $0 \%$ \\
\hline Time & Within $48 \mathrm{~h}$ & 0 & $0 \%$ \\
& $>5$ days postoperative & 4 & $100 \%$ \\
\hline
\end{tabular}

In this study, Gastric leak was the most common acute post-operative complication (in the end of first week) followed by internal hemorrhage. Abscess formation was the commonest complication in the second week followed by Porto-mesenteric vein thrombosis in the third week. (Table-4). 
Table (4): Time of occurrence of complication

\begin{tabular}{|l|c|c|c|}
\hline \multirow{2}{*}{ Complication } & \multicolumn{3}{|c|}{ Timing } \\
\cline { 2 - 4 } & $1^{\text {st }}$ week & $2^{\text {nd }}$ week & $3^{\text {rd }}$ week \\
\hline Leak & 4 & - & - \\
\hline Abscess & - & 2 & - \\
\hline hematoma & 2 & - & - \\
\hline Pleural effusion & 2 & - & - \\
\hline Porto-mesenteric vein thrombosis & - & 1 & 1 \\
\hline Splenic infarction & 1 & - & - \\
\hline Splenic injury & 1 & - & - \\
\hline Wound infection & - & 1 & - \\
\hline
\end{tabular}

Clinical presentations of common common clinical presentation associated complications are mentioned in Table 5. with leak. (Table-5).

Tachycardia and fever were the most

Table (5): Clinical presentation of complications

\begin{tabular}{|l|l|}
\hline Complication & Symptoms \& signs \\
\hline Leak & Tachycardia \& fever \\
Porto-mesenteric thrombosis & Vomiting \& abdominal pain \\
Abscesses & Fever \\
Internal hemorrhage & Tachycardia \\
Splenic injury & Abdominal pain \\
Pleural effusion & Dyspnea and tachypnea \\
Wound infection & pain \\
\hline
\end{tabular}

\section{DISCUSSION:}

LSG is one among different bariatric surgeries, which became an effective treatment method for morbid obesity. Early detection of complications after LSG is critical in the postoperative period, as it may allow prompt and potentially less invasive management $^{[1]}$.

This study included 25 patients. CT was done for patients with clinically or radiologically suspected complication, even in the presence of negative UGI series. Complications were detected in 15 patients out of the 25 patients $(60 \%)$, with no mortality.

In the current study, post-operative leak was the most common complication $16 \%$ followed by hematoma $8 \%$, abscess formation $8 \%$ and Porto-mesenteric vein thrombosis $8 \%$. Reports of gastric leak after
LSG have been within the range of $0.7-$ $5.3 \%{ }^{[10]}$.

In the current study post-operative leaks occurred in early post-operative period within the $1^{\text {st }}$ week, which is in agreement with Brockmeyer, et al. who stated that the etiology of post-operative leak has been divided into mechanical or technical errors occurring within $48 \mathrm{~h}$ and ischemic for leaks occurring 5-7 days after surgery ${ }^{[11]}$.

In addition, Chivot et al. explained the incidence of leaks in the $1^{\text {st }} 48 \mathrm{~h}$ due to mechanical or technical errors while for late onset (within 5-7 days) due to ischemia caused by tension and poor wound healing, in both scenarios, the intraluminal pressure exceeds the potency of the tissues and staple lines resulting in a leak ${ }^{[12]}$. Sakran et al. demonstrated that the median postoperative day for clinical diagnosis of a leak after LSG was day 7 , with early (0-2 days), inter- 
mediate (3-14 days), and late (4-14 days) presentation in $20 \%, 73 \%$, and $7 \%$ of patients, respectively ${ }^{[13]}$. Csendes et al. mentioned three categories of gastric leak, the first early leaks appear in 1-4 days after surgery, intermediate leaks appear 5-9 days after surgery and late leaks appears 10 days or later after surgery ${ }^{[14]}$.

Sethi et al. reported 20 gastric leaks after 1762 LSG procedures, with $11 \%$ sensitivity for the UGI series. They concluded that contrast extravasation on routine postoperative radiological UGI series may detect early staple line leaks after LSG, but the vast majority of leaks show normal results on postoperative UGI series and present 2 to 3 weeks after discharge ${ }^{[15]}$.

In this study, pneumo-peritoneum and intra-peritoneal extravasation of oral contrast were found in all cases of leaks which
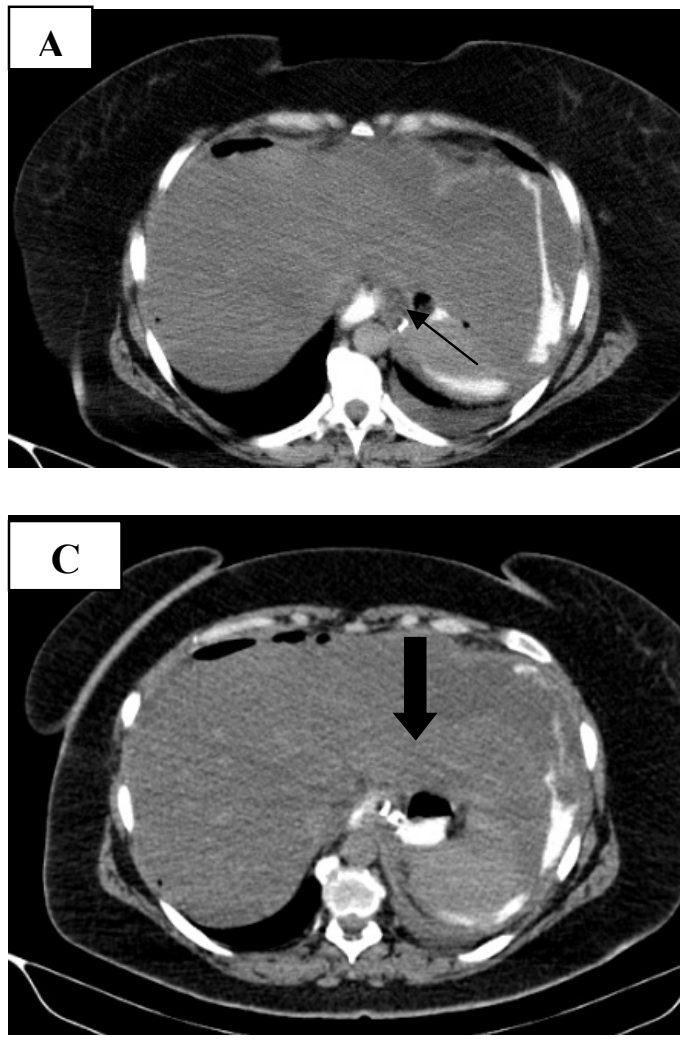

agreed with the results of Kim et al. who mentioned that localized fluid collection or abscess may be the only sign of leak and must be distinguished from transient postoperative serum collection ${ }^{[16]}$.

This study found the most common site of leak was proximal part of stomach. Deitel et al. stated that post-operative leak has been observed in the upper part of the sleeve in $1.3 \%$ of cases and in the lower part in $0.5 \%$ of cases ${ }^{[17]}$.

Contrast leak occurred along the staple line and in the sub-phrenic area in agreement with Baker et al. who explained this preferential site by mobilization of the greater curvature of the stomach after transection of gastro-colic and gastro-splenic ligaments, establishing a communication between the lesser sac and the left sub-phrenic space ${ }^{[18]}$.
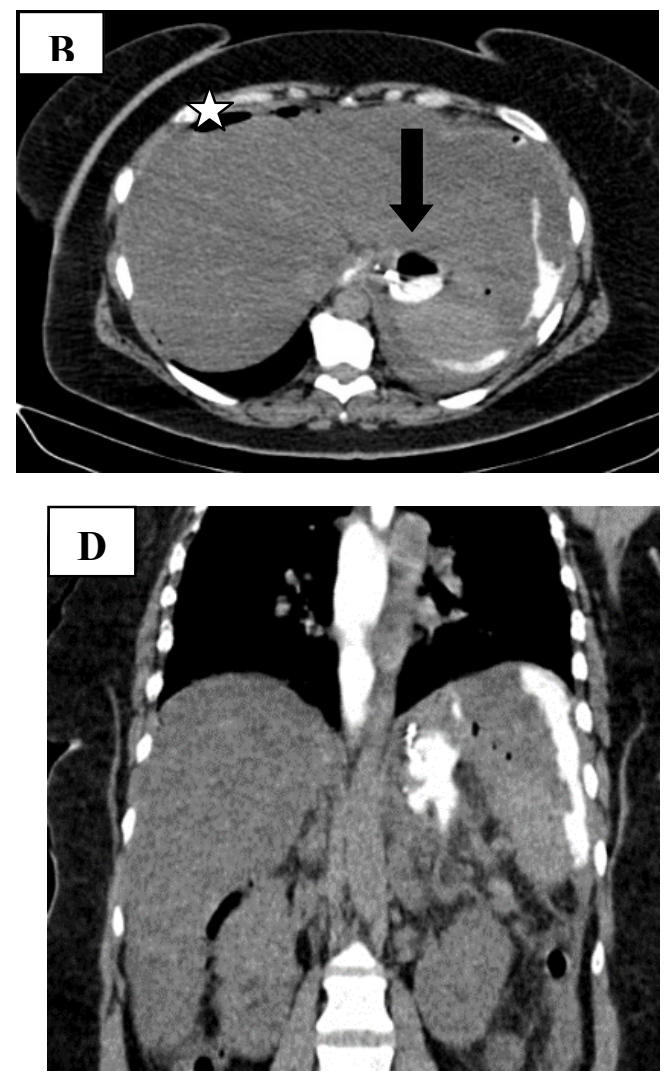

Fig (1): Post LSG female patient with upper staple line leakage: axial images (A-C images) and Coronal images (D images) showing staple line (small arrow in A), a large collection with air-fluid level near upper staple line (thick arrow in $\mathrm{B}$ and $\mathrm{C}$ ), contrast collection at the perisplenic region (arrow head in D) and air within peritoneum (star shape in A) . 
Abdominal pain, tachycardia and fever were the most common clinical presentation associated with leak in the current study. Previous studies have shown that clinical symptoms such as tachycardia, abdominal pain, and respiratory distress are highly suggestive of gastric staple line leak after bariatric surgery. Of our 4 patients diagnosed with a staple line leak, 2 presented with abdominal pain uncontrolled by analgesic treatment, 1 with increased body temperature, and 1 with tachycardia. [15].

In the current study, abscess occurred in 2 cases (8\%) among the study group and was located in the sub-phrenic space in agreement with Deitel et al. who reported similar incidence. It was treated by CTguided percutaneous drainage with suitable antibiotic coverage ${ }^{[17]}$.
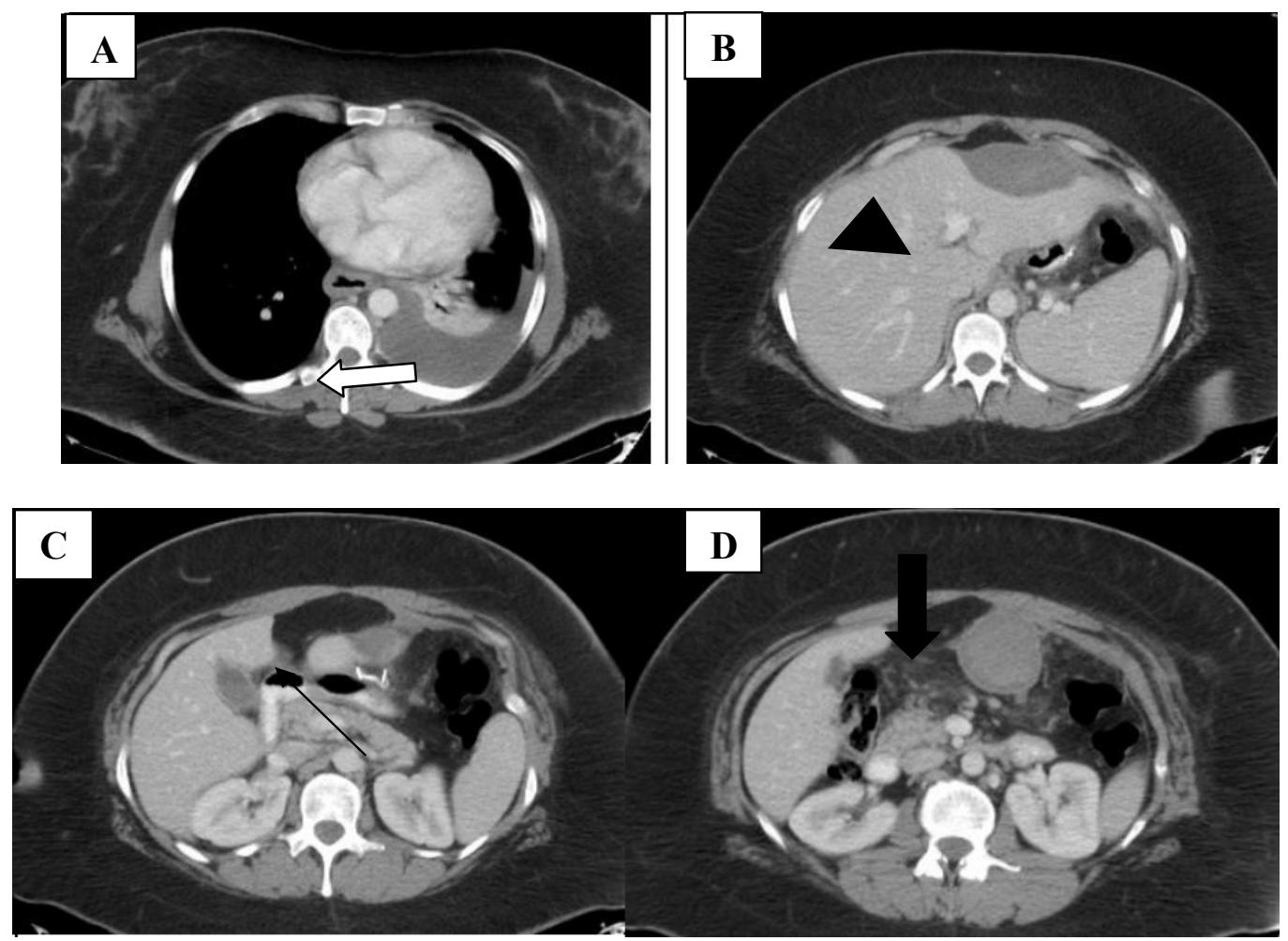

Fig (2): Post LSG peritonitis with abscess formation and Moderate left sided pleural effusion. Axial CT images (A-D) demonstrating intra-peritoneal abscess (thick arrow in D), left sided pleural effusion (white arrow in A), hepatic sub-capsular hematoma (arrow head in B) and staple line (thin arrow in A).

In the current study, hematoma was detected by $\mathrm{CT}$ in 2 cases $(8 \%)$. Melissas et al. reported the risk of postoperative bleeding to be between $1 \%$ and $6 \%$ after LSG. The source of bleeding can be extraor intra-luminal. Intra-luminal bleeding from the staple line usually presents with an upper gastrointestinal bleed ${ }^{[19]}$.

Hematoma occurred within $24 \mathrm{~h}$ in 1 case while the other case occurred within 7 days postoperatively and $\mathrm{CT}$ reveals fluid collection encircling the stable line. The majority of hematomas remain asymptomatic, because in reality they contain only a small quantity of blood. Hemodynamic symptoms occur in large hematomas, which in the majority of cases occur after discharge. Early detection of hematoma is paramount for favorable outcome since under certain circumstances they can render the staple line more fragile and promote abscess and late staple line leak formation [20]. 
Splenic infarction was detected by CT in one case (4\%) and was discovered 12 days postoperative. Splenic injury also occurred in one case (4\%) in agreement with Chivot et al. who reported similar incidence. Splenic infarction may be explained by injury or occlusion of peripheral splenic arterial branches when the surgeon exposes the greater curvature and separately coagulates the short gastric vessels close to the spleen ${ }^{[12]}$.

Portal vein thrombosis was detected in 2 cases $(8 \%)$ and these 2 cases were discovered within 2-3 weeks postoperatively. These 2 patients were treated by long term anticoagulant therapy. Bradbury et al. stated that portal vein thrombosis is an uncommon complication following LGS and diagnosis can be established with contrast-enhanced CT or color Doppler ultrasonography ${ }^{[21]}$. Jacob et al. stated that as the prevalence of bariatric surgery continues to increase, PVT might become an increasingly identified diagnosis [22].
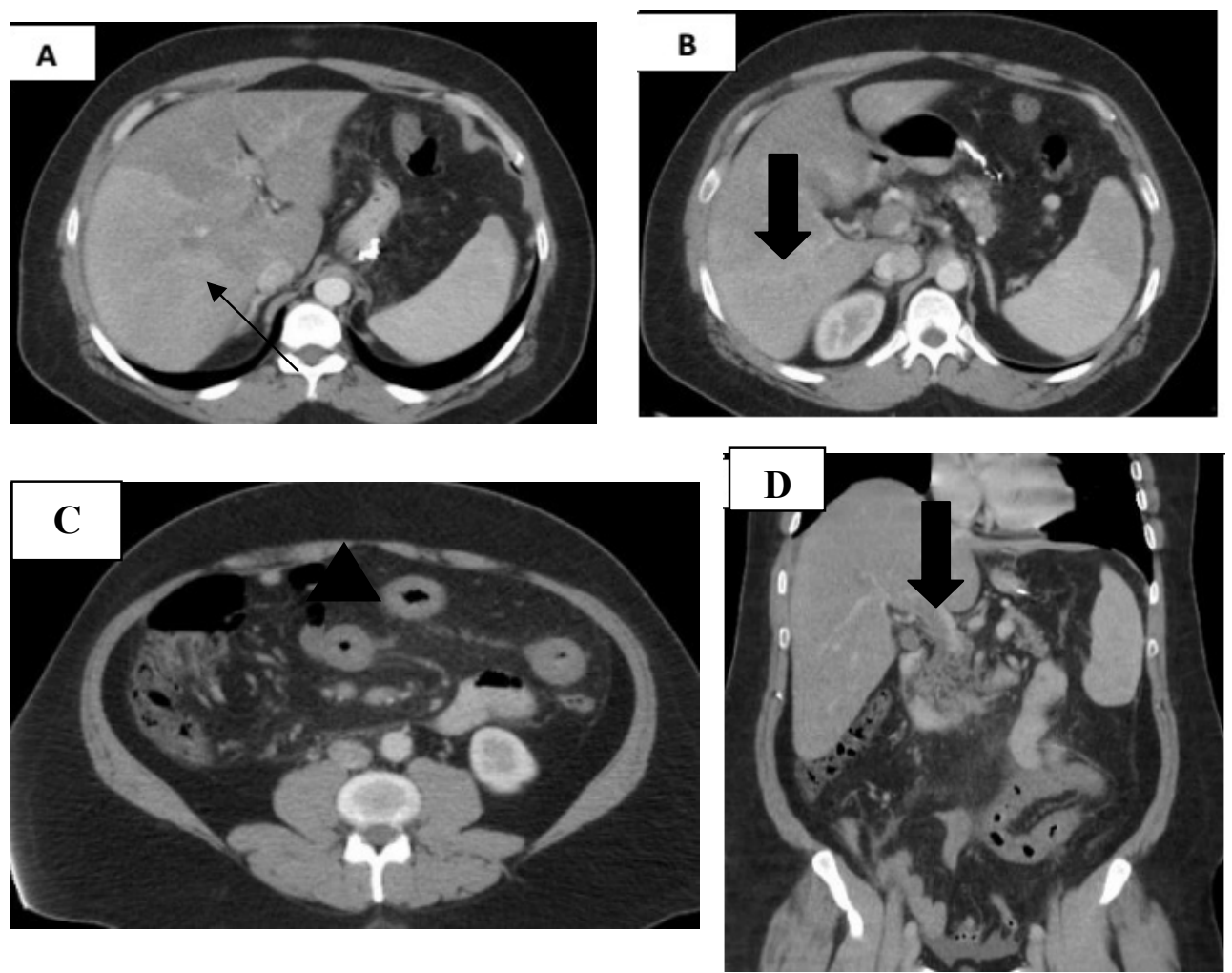

Fig (3): Post LSG portal, mesenteric and splenic veins thrombosis. Axial contrast enhanced CT images (images A-C) and Coronal CT reconstructed image (Image D). Staple line (thin arrow in A) Distended PV by non-enhancing thrombus extending to superior mesenteric vein and splenic veins (thick arrow in B and D). Thickened and edematous bowel loops (arrow head).

The current study showed great feasibility of MDCT in detecting certain complications that give a good opportunity to surgeon for proper management, as portomesenteric venous thrombosis, splenic injury and post-operative hemorrhage, where UGI series were negative and these results are in agreement with Chivot et al. who stated that UGI series does not detect abscesses, hematomas and small leak as well as systemic complications ${ }^{[12]}$.

In this study, CT was very helpful in detecting abscess, infection and effusion which cannot be detected by UGI series. 
Moreover, CT allows to diagnose complications and to adapt the therapeutic strategy. Taking into account the complication severity of gastric staple line leak in LSG patients, CT scan was the most efficient pathway to prompt treatment for these patients.

The current study agree with Chivot et al. who reported that in the presence of a high clinical doubt of complications, and even when postoperative UGI images are normal, CT has to be performed to search for other associated complications such as abscess and fistula. CT can also provide other important data by showing pneumoperitoneum or extra-luminal accumulation of oral contrast material; however, pneumoperitoneum alone is an extremely common postoperative finding. CT is considered the examination of choice in those patients with post-operative vague abdominal symptoms $^{[12]}$.

\section{In conclusion:}

As LSG is performed increasingly and frequently, it is essential for radiologists to understand the normal postoperative anatomy and recognize the complications of this procedure. In most of the centers UGI studies remain the first-line imaging modality for follow-up. CT is an important imaging tool to diagnose suspected complications of laparoscopic sleeve gastrectomy procedure and should be usedto ensure accurate diagnosis or in the case of mismatch between symptoms and routine upper GIT studies.

\section{REFERENCES}

1. Irene $\mathrm{T}$ M, James A $\mathrm{M}$. Gastrointestinal Complications After Bariatric Surgery. Gastroenterol Hepatol (N Y). 2015 Aug; 11 (8): 526-535.

2. Bhurosy $\mathrm{T}$, Jeewon R. Overweight and Obesity Epidemic in Developing Countries: A Problem with Diet, Physical Activity, or Socioeconomic Status?.Scientific World
Journal. 2014; 2014: 964236.

3. Jepsen R, Aadland E, Robertson L, Kolotkin R, Anderse J R, Natvig G K. Physical Activity and Quality of Life in Severely Obese Adults during a Two-Year Lifestyle Intervention Programme. J Obes. 2015; 2015: 314194

4. Benaiges D, Más-Lorenzo A, Goday A, Ramon JM, Chillarón JJ, Pedro-Botet J, et al. Laparoscopic sleeve gastrectomy: More than a restrictive bariatric surgery procedure? World J Gastroenterol. 2015; 21:11804-14.

5. Chang SH, Stoll CR, Song J, Varela JE, Eagon CJ, Colditz GA. The effectiveness and risks of bariatric surgery: an updated systematic review and meta-analysis, 20032012. JAMA Surg. 2014; 149:275-87.

6. Kourosh S, Daniel W, Birch et al. Complications associated with laparoscopic sleeve gastrectomy for morbid obesity: a surgeon's guide .Can J Surg. 2013; 56: 347-352.

7. Riaz RM, myers DT, Williams TR. Multidetector CT. imaging of bariatric surgical complications: apictoral review. Abdom Radiol 2016: 41:174-88.

8. Safadi BY, Shamseddein G, Elias E, Alami RS. Definitive surgical management of staple line leak Dis 2015:11:1037-43.

9. Levine MS, Rarucci LR. imaging of bariatric surgery (normal anatomy and postoperative complications), radiographics, 2014, volume 270:,327-341.

10. vanRutte PW, Smulders JF, de Zoete JP, Nienhuijs SW. Outcome of sleeve gastrectomy as a primary bariatric procedure. Br J Surg 2014; 101:661-8.

11. Brockmeyer JR, Simon TE, Jacob RK, Husain F, Choi Y. Upper gastrointestinal swallow study following bariatric surgery: institutional review and review of the literature. ObesSurg 2012; 22:1039-43.

12. Chivot C1, Robert B, Lafaye N, Fuks D, Dhahri A, Verhaeghe P, et al. Laparoscopic sleeve gastrectomy: imaging of normal anatomic features and postoperative gastrointestinal complications. DiagnInterv 


\section{Mohamed Shaker Ghazy, et al.,}

Imaging. 2013;94:823-34.

13. Sakran N, Goitein D, Raziel A, et al. Gastric leaks after sleeve gastrectomy: a multicenter experience with 2,834 patients. SurgEndosc 2013;27:240-5.

14. Csendes A, Braghetto I, Leon P, Burgos AM. Management of leaks after laparoscopic sleeve gastrectomy in patients with obesity. Journal of Gastrointestinal Surgery. 2010; 14:1343-8

15. Sethi M, Magrath M, Somoza E, Parikh M, Saunders J, Ude-Welcome A et al. The utility of radiological upper gastrointestinal series and clinical indicators in detecting leaks after laparoscopic sleeve gastrectomy: a case-controlled study. SurgEndosc. 20163:2266-75.

16. Kim KW, Choi BI, Han JK, Kim TK, Kim $\mathrm{AY}$, Lee HI, et al. Postoperative anatomic and pathologic findings at CT following gastrectomy. Radiographics 2002;22:32336.

17. Deitel M, Gagner M, Erickson AL, Crosby RD. Third international summit: current status of sleeve gastrectomy. Surg Obes
Relat Dis 2012;7:749-59.

18. Baker RS, Foote J, Kemmeter P, Brady R, Vroegop T, Serveld M. The science of stapling and leaks. ObesSurg 2004; 14; 1290-8.

19. Melissas J, Koukouraki S, Askoxylakis J, et al. Sleeve gastrectomy: A restrictive procedure? Obes Surg. 2007; 17:57-62.

20. Lainas P, Tranchart H, Gaillard M, Ferretti S, Donatelli G, Dagher I. Prospective evaluation of routine early computed tomography scanner in laparoscopic sleeve gastrectomy. Surg Obes Relat Dis. 2016; 1483-1490.

21. Bradbury MS, Kavanagh PV, Bechtold RE, Chen MY, Ott DJ, Regan JD, et al. Mesenteric venous thrombosis: diagnosis and noninvasive imaging. Radiographics $2002 ; 22: 527-41$.

22. Jacob MR, Maureen T, Dorcas CY, Dan E. Portal vein thrombosis following laparoscopic sleeve gastrectomy for morbid obesity. J SocLaparoendoscSurg (JSLS) 2012; 16:639.

\section{دور الاشعة المقطية متعددة المقاطع فى تقييم المضاعفات المبكرة لجراحة تكميم المعدة فى مرضى

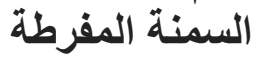

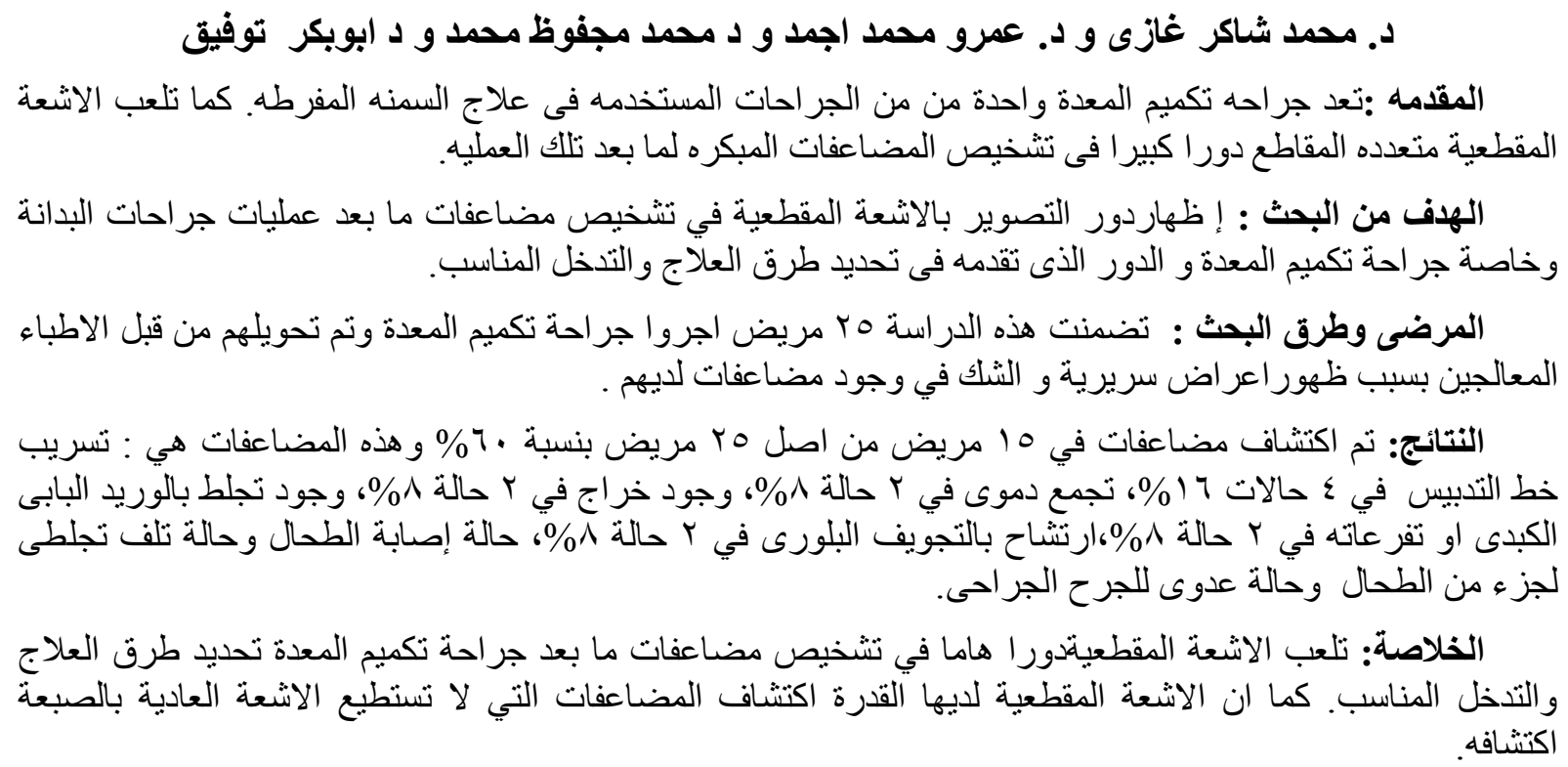

